\title{
Diagnosis and management of secondary-progressive multiple sclerosis: time for change
}
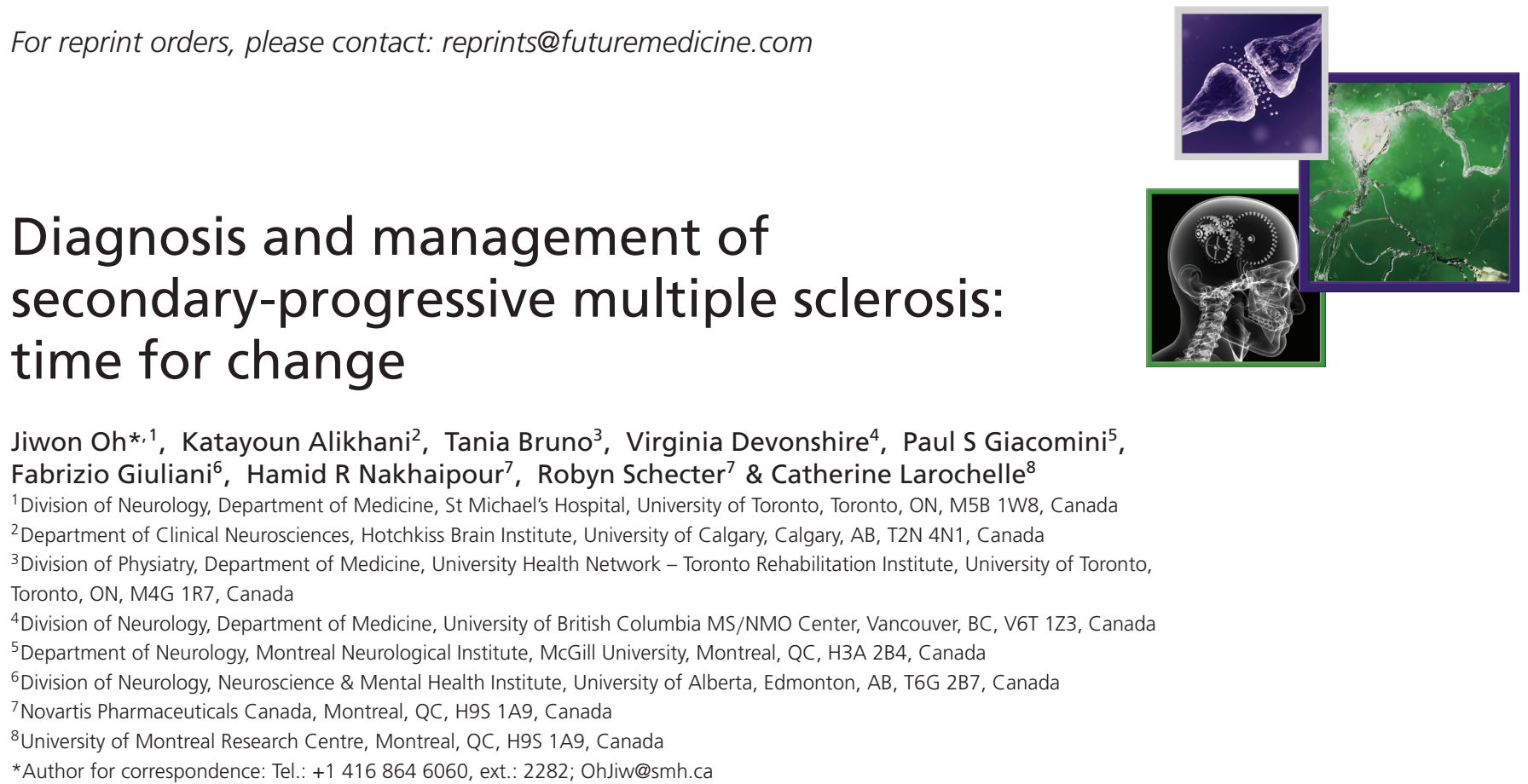

\section{Practice points}

- There are four key stages in the transition from relapsing-remitting multiple sclerosis to secondary-progressive multiple sclerosis (SPMS): recognizing the early signs associated with transition, establishing a diagnosis of SPMS, developing a management plan and disease monitoring.

- The transition to SPMS typically invokes strong emotional responses that are unique to each patient.

- Most patients and caregivers wish to be informed and educated through these stages.

- Therapeutic agents specifically approved for the management of SPMS patients are needed.

- Nurses/nurse practitioners and other allied healthcare professionals are essential at all stages of disease progression. This interdisciplinary team can assist with patient education, support and nonpharmacological management.

Identifying the transition of relapsing-remitting multiple sclerosis (MS) to the secondary-progressive MS form remains a clinical challenge due to the gradual nature of the transition, superimposed relapses, the heterogeneous course of disease among patients and the absence of validated biomarkers and diagnostic tools. The uncertainty associated with the transition makes clinical care challenging for both patients and physicians. The emergence of new disease-modifying treatments for progressive MS and the increasing emphasis of nonpharmacological strategies mark a new era in the treatment of progressive MS. This article summarizes challenges in diagnosis and management, discusses novel treatment strategies and highlights the importance of establishing a clear diagnosis and instituting an interdisciplinary management plan in the care of patients with progressive MS.

First draft submitted: 8 October 2019; Accepted for publication: 7 November 2019; Published online: 26 November 2019

Keywords: biomarkers $\bullet$ disease-modifying therapy $\bullet$ inflammation $\bullet$ neuroprotective $\bullet$ secondary-progressive multiple sclerosis

"The accurate diagnosis of multiple sclerosis may be one of the easiest in medicine to make in some instances, but on other occasions it may be one of the most diffccult." - Guy H Williams Jr, 1967 [1]

52 years after the publication of Dr Williams' paper, many aspects of multiple sclerosis (MS) remain an enigma. Despite its high global prevalence and recognition as a leading cause of nontraumatic disability in individuals aged 20-50 years [2-4], the diagnosis and clinical management of various subtypes of MS continue to be a challenge in some cases. This is likely related to the heterogeneous clinical presentation and pathology. 
Approximately $85 \%$ of patients are diagnosed with a relapsing-remitting (RR) form of MS at first presentation $[4,5]$. Without disease-modifying treatment (DMT), natural history studies have shown that the majority of RRMS patients advance to a progressive phase of disease that is associated with accrual of significant disability [6-8]. However, the significant interpatient variability in duration and symptom intensity of the RR phase greatly complicates early diagnosis and optimal patient support and management through the transition into secondary-progressive MS (SPMS) [9].

The objective of this review is to discuss salient points regarding the transition from RRMS to SPMS, focusing on the perspectives of patients, caregivers, physicians and nurse/nurse practitioners in the pretransition stage, at diagnosis of SPMS, and in the long-term management and monitoring of the patient's condition.

\section{Pathophysiology}

It is well established that MS is a chronic, immune-mediated, demyelinating disease, characterized by infiltration of autoreactive immune cells into the CNS [10-13]. The precise causative mechanisms leading to the progressive phase of disease from RRMS remain elusive; however, several characteristic processes have been suggested [14]. Numerous studies support both age-associated cumulative neurodegeneration and unique CNS pathology as the underlying initiators of progression [15].

Common pathological characteristics among RRMS, SPMS and primary-progressive MS (PPMS) include inflammation, demyelination/remyelination, neurodegeneration and glial scar formation; however, these elements vary qualitatively and quantitatively between MS subtypes and between patients with the same subtype [16]. In earlier-stage MS, T and B lymphocytes and myeloid cells migrate across the blood-brain barrier from the peripheral blood toward the CNS compartment, where they activate microglia and cause damage to neuroglial cells, leading to the formation of active lesions [17-19]. In early MS, the volume of demyelinating lesions is greater in the white than the gray matter (GM), while progressive MS is characterized by extensive GM demyelination [20]. Focal GM atrophy was shown to be an early marker of progression [21], and the rate of GM atrophy correlated with advancing MS stage [22-24].

Progressive MS is associated with the formation of lymphoid-like 'meningeal follicles' within the CNS containing $\mathrm{T}$ and $\mathrm{B}$ cells, plasma cells and dendritic cells. Meningeal inflammation promotes the formation of subpial demyelinated lesions, and there is a slow expansion of existing white matter lesions and diffuse neurodegeneration in normal-appearing white and GM of the brain and spinal cord. Smoldering, inactive and shadow plaques have been predominantly observed in progressive MS and are age-associated, with an equilibrium achieved between active and inactive plaques at approximately 47 years of age [19]. The compartmentalized inflammatory response in progressive MS correlates with a significant reduction of damage to the blood-brain barrier relative to RRMS, and this inflammation localized within the CNS may explain the loss of benefit with traditional DMTs $[15,25,26]$. Remyelination, while heterogeneous among patients, is generally reduced with progressive disease and also depends on lesion site $[27,28]$.

\section{Natural history}

Natural history studies have demonstrated that most untreated RRMS patients eventually progress to SPMS $[8,29,30]$. Tutuncu et al. found that $62 \%$ of RRMS patients had transitioned to SPMS by 75 years, with the average age of onset of progression being 45 years [8]. Older age at onset and longer MS duration are the most significant risk factors associated with progressive disease [29-31]. The British Columbia Multiple Sclerosis database $(\mathrm{N}=5778)$ revealed a median time to SPMS of 21 years and a median age at onset of 54 years [30]. A predictive model developed by Manouchehrinia et al. estimated the risk of SPMS conversion at 10, 15 and 20 years based on the patient's sex, year of birth, baseline Expanded Disability Status Scale (EDSS) score, age at the first EDSS and age at disease onset [32]. Other clinical risk factors associated with earlier onset of SPMS include incomplete recovery from the first MS attack, high relapse rate after disease onset, multifocal clinical manifestations of relapses, the presence of brainstem and/or infratentorial lesions, a high rate of brain atrophy, smoking history and low vitamin D levels [15].

In most cases, the transition from RRMS to SPMS is a gradual process marked by reduction in the number of relapses but progressive neurological deterioration; however, this transition is highly variable. Overlap between RRMS and SPMS is a frequent occurrence, with up to $30 \%$ of patients experiencing relapses after progression has begun [33]. 


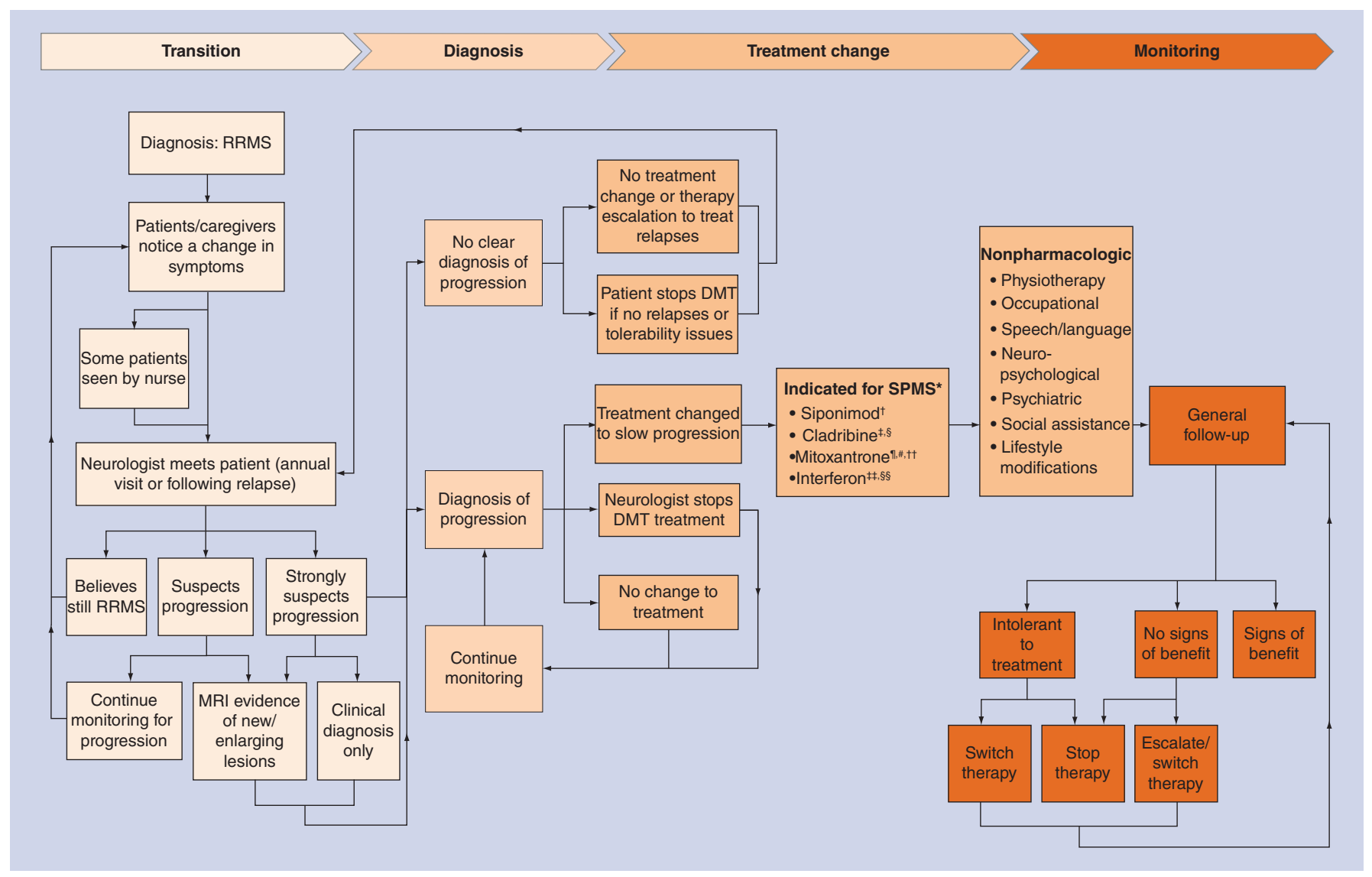

Figure 1. The journey of secondary-progressive multiple sclerosis patients.

${ }^{\dagger}$ Agents are not approved in some countries.

¥Indicated by the US FDA for the treatment of relapsing forms, including active secondary-progressive multiple sclerosis (SPMS).

$\S$ Indicated by the EMA for the treatment of highly active relapsing multiple sclerosis (MS).

$\mathbb{I}$ Indicated by the FDA for the reduction of neurologic disability and/or the frequency of clinical relapses in patients with SPMS, progressive relapsing or worsening RRMS.

\#Indicated by the EMA for highly active relapsing MS associated with rapidly evolving disability where no alternative therapeutic options exist.

${ }^{\dagger}$ Mitoxantrone should be initiated only if it is determined that the potential benefits outweigh the risks of this therapy.

$\ddagger \ddagger$ IFN- $\beta-1 b$ is approved by the EMA and Health Canada for the management of SPMS patients; IFN- $\beta-1 a$ (Rebif ${ }^{\circledR}$ ) is approved in Canada for relapsing forms of MS.

$\S \S$ IFN- $\beta-1$ a and $\beta-1$ b are approved by the FDA for relapsing forms of MS.

DMT: Disease-modifying treatment; RRMS: Relapsing-remitting multiple sclerosis.

\section{The patient journey from RRMS to SPMS}

The transition from RRMS to SPMS can be divided into four general stages (Figure 1), although there is considerable overlap. Throughout the disease course of MS, the patient should be a key contributor to management decisions, and interdisciplinary care is essential [34-36]. This strategy is even more relevant as the patient transitions to SPMS. A proposed physician action plan for each stage is presented in Table 1.

\section{Transition phase}

Patients \& caregivers

The onset of signs and symptoms associated with the transition to SPMS can elicit a variety of cognitive, emotional and behavioral responses. Several series of semistructured interviews with SPMS patients have identified a number of themes. The first is uncertainty regarding whether the subtle change in the patient's pattern of MS represented progression ('is this really happening?') [37-40]. Small, gradual changes in a patient's disease course were often only identified retrospectively after the diagnosis of progressive MS [37]. Some patients shared that they tried to ignore 
Table 1. Physician action plan.

\begin{tabular}{|c|c|c|c|}
\hline Transition & Diagnosis & Management & Monitoring and follow-up \\
\hline $\begin{array}{l}\text { - Initiate an ongoing and open } \\
\text { discussion with patients and caregivers } \\
\text { about SPMS even before the patient } \\
\text { shows signs of progressive disease } \\
\text { - Actively seek signs and symptoms of } \\
\text { SPMS during clinical visits. } \\
\text { - Provide evidence-based educational } \\
\text { materials, such as those made available } \\
\text { by the National Multiple Sclerosis } \\
\text { Society (https://www.nationalmssociety. } \\
\text { org/Resources-Support/Library-Educatio } \\
\text { n-Programs/Brochures), Multiple } \\
\text { Sclerosis Association of America } \\
\text { (https://mymsaa.org/ms-information/pu } \\
\text { blications), MS Society of Canada } \\
\text { (https://mssociety.ca/about-ms) or other } \\
\text { national MS associations } \\
\text { - Ensure that the patients and } \\
\text { caregivers have ample opportunity to } \\
\text { pose questions and raise concerns }\end{array}$ & $\begin{array}{l}\text { - A prompt, clear diagnosis of SPMS is } \\
\text { invaluable for both the patient and } \\
\text { physician as it enables optimal and } \\
\text { timely clinical management decisions to } \\
\text { be made } \\
\text { - Inform patients in a sensitive and } \\
\text { empathic manner that their disease is } \\
\text { progressing [38]. Patients should be } \\
\text { given adequate time to take in this } \\
\text { information and pose any questions } \\
\text { - It may be beneficial to give the } \\
\text { diagnosis of SPMS as a gradual } \\
\text { reframing process as symptoms progress } \\
\text { rather than in a single interaction [46] } \\
\text { - Emphasize the emergence of } \\
\text { evidence-based treatments that have } \\
\text { demonstrated effectiveness in RRMS } \\
\text { and SPMS. Patients have expressed a } \\
\text { high desire to receive information } \\
\text { about new therapeutic options [75] }\end{array}$ & $\begin{array}{l}\text { - Pharmacotherapeutic options are } \\
\text { expanding in the management of SPMS. } \\
\text { These agents are best combined with } \\
\text { symptom-specific treatments, managing } \\
\text { co-morbidities and nonpharmacological } \\
\text { therapies for holistic patient care } \\
\text { - Interdisciplinary management } \\
\text { strategies should be utilized when } \\
\text { appropriate in all SPMS patients } \\
\text { - Shared treatment decision-making } \\
\text { with the informed patient and } \\
\text { caregiver is essential to ensure that } \\
\text { each individual's key therapeutic } \\
\text { objectives are addressed }\end{array}$ & $\begin{array}{l}\text { - Continued communication with } \\
\text { patients, caregivers and other allied } \\
\text { health professionals is essential to } \\
\text { understand disease progression and to } \\
\text { monitor treatment effect and adjust care } \\
\text { plans accordingly } \\
\text { - Ongoing support by an interdisciplinary } \\
\text { team is key to preserve maximum HRQoL } \\
\text { for both patients and caregivers }\end{array}$ \\
\hline
\end{tabular}

or deny the prospect of progression, while others sought information on SPMS in an attempt to brace themselves for this possibility [37,38].

Another theme that emerged is that patients are frequently reluctant to report a change in symptoms due to fear of progression $[41,42]$. Additional reasons for lack of reporting may include downplaying the importance of these highly individualized and often subtle changes, and anxiety about the implications regarding changes in treatment regimen.

Early realization of progression is typically more challenging for caregivers, who usually rely on the information they receive from the patient [38]. As progression becomes more pronounced, caregiver burden typically increases [43]. Caregiver distress and reduced quality of life (QoL) relate closely to the patient's psychiatric symptoms and cognitive impairment and, to a lesser degree, to physical impairment [44].

\section{Neurologists}

For clinicians, recognizing the transition to SPMS is frequently lengthy and fraught with uncertainty. While some diagnostic criteria suggest a significant change in EDSS as early as 3 months $[45,46]$ that may signify the transition to SPMS, the average time from the first sign of progressive disease to the official diagnosis of SPMS was estimated to be approximately 3 years [47]. Reasons for this delay include the heterogeneity of MS, subtlety of symptoms, overlap between SPMS and RRMS, and the absence of validated biomarkers of progression [37,47-49]. A recent review paper outlined the ongoing challenge of defining progressive disease and SPMS [44].

A small, single-physician study revealed that because of diagnostic uncertainty, frequent medical visits were required with patients in whom SPMS was eventually identified [47]. In a semistructured interview with a spectrum of healthcare professionals, physicians described their preference of being conservative in making the diagnosis rather than making a diagnostic error [49].

\section{Nurses/nurse practitioners \& other allied health professionals}

Allied healthcare personnel often play an active role in the recognition of symptoms that may signify the transition phase and often dialogue with patients around this possibility [49]. Some allied health professionals have described their role around transition and diagnosis as 'planting a seed' for the patient to consider progression of symptoms, such as prompting them to reflect on the reduction in their ability to perform normal activities of daily living [49].

\section{Diagnosis}

In addition to the significant uncertainty and heterogeneity associated with the preliminary symptoms of SPMS, establishing a definitive diagnosis is impeded by the absence of clear clinical, imaging, immunologic or pathologic criteria to identify the transition to SPMS [43]. Thus, SPMS remains a diagnosis that is based entirely on clinical judgment [48]. 
MRI is an established diagnostic tool for MS. While current MRI techniques are largely unreliable in the prediction of progression $[43,50,51]$, longitudinal studies have found that the volume and change of $\mathrm{T}_{2}$-hyperintense lesions in the first 5 years of MS diagnosis were useful in the prediction of increased EDSS at 14 years and subsequent 20-year disability [52,53]. Furthermore, emerging imaging biomarkers, including measuring spinal cord atrophy and other quantitative techniques in the brain, may eventually become useful [54,55].

The association between cerebrospinal fluid (CSF) oligoclonal bands (OCBs) and MS has been known for decades [56], and the presence of intrathecal OCBs is a widely used diagnostic biomarker for MS [57,58]; however, evidence generally does not support the utility of CSF OCBs as a marker of progression to SPMS [59-61]. Emerging biological markers - including neurofilament light chain levels in serum or CSF [62-64], CSF sCD27 [65], chemokine (C-C motif) ligand 18 plasma levels [66] and the MS risk allele $H L A-D R B 1^{*} 15$ [67] - have shown some promise in the identification of those at higher risk of progression; however, none have been validated to date. Chitinase 3-like-1 has been shown to be associated with conversion of patients with clinically isolated syndrome to MS, onset of neurological disability and risk of long-term cognitive impairment [68,69]. While Chitinase 3-like-1 concentration was associated with brain volume loss [70], its association with progression was not significant [62]. Although promising, the data on these potential markers of progressive disease are limited by small numbers of subjects and variance in study methodology [71]. As such, validation in larger-scale trials is necessary before they can be utilized clinically.

\section{Patients \& caregivers}

The confirmation of SPMS generally elicits a spectrum of responses in patients. Many express feelings of devastation and loss of hope [37-39]. One report described the impact of confirming SPMS as being 'diagnosed all over again' [39]. Greater knowledge about SPMS was found to be associated with more positive patient outlooks about their transition [37,38,72]. Some described feeling relief and a greater ability to make sense of their condition and that the diagnosis was a pivotal point for heightened acknowledgment of their MS [37], and other accepted the transition as an expected part of MS [73]. The initial delay and lack of transparency in reclassification were noted as points of frustration and anxiety, and some subjects expressed a sense of insufficient support and abandonment $[37,38,73,74]$. Patients and caregivers also shared their wish that the method of diagnosis had been explained to them and that their physician had provided information on the potential clinical impact of SPMS, strategies to maximize health and function, and available resources [38]. In addition to education about SPMS, caregiver support should include advice, emotional support and training in caregiver skills and tasks [75]; however, few caregivers are offered support for themselves [38]. Healthcare practitioners should proactively discuss caregiver burden and burnout, and recommend resources for the caregiver, whenever available.

\section{Neurologists}

The uncertainty that prevents early recognition of progression frequently results in delays with confirming the diagnosis and subsequently informing patients. Discussing the diagnosis of SPMS often requires physicians to spend a great deal of time and emotional energy, as there is concern about the psychological effect of this diagnosis on patients [37,76]. Some physicians may be hindered by a sense of defeat when faced with a progressing MS patient [77]. Implications for health insurance coverage, fear of a chart audit and reduced opportunity to have the patient seen by a neurologist when 'labeled' with a diagnosis of SPMS may also delay the confirmation of this diagnosis $[47,49,74,78]$.

\section{Nurses/nurse practitioners \& other allied health professionals}

The nurse/nurse practitioner serves important roles in education, encouragement and psychosocial and selfmanagement support for both patients and caregivers when diagnosed with SPMS [37,39,79,80]. Nurses are often skilled in this role as they commonly develop trust-based relationships with patients, and are therefore able to help them cope with the diagnosis $[81,82]$. They are typically also skilled in explaining complex information in a manner that is easily comprehensible for patients and caregivers [82].

\section{Management}

Pharmacological

Siponimod, a selective modulator of sphingosine-1-phosphate receptor subtypes 1 and 5, was recently approved by the FDA for the management of active SPMS [83]. Siponimod was shown in the EXPAND study to significantly 
reduce the incidence of confirmed disability progression at 3 and 6 months (hazard ratio: 0.79 and 0.74 , respectively) compared with placebo in patients with SPMS [84]. Siponimod-treated patients also experienced significantly less total brain volume loss and total brain lesion increase at 12 and 24 months. A long-term (up to 10 years), open-label extension of EXPAND is ongoing.

Cladribine also received recent FDA approval for relapsing forms of MS, including RRMS and active SPMS [85]. It has been approved for RRMS in Europe and Canada since 2017 [86,87]. The European Committee for Treatment and Research in Multiple Sclerosis (ECTRIMS) guidelines recommend consideration of cladribine in SPMS patients [88]. The CLARITY study determined that cladribine significantly reduced relapse rates, risk of progression of disability and MRI-measured disease activity in RRMS patients [89]; however, no studies have been conducted to date in an exclusive SPMS population.

Mitoxantrone is approved by the FDA for the reduction of neurologic disability and/or the frequency of clinical relapses in SPMS patients, and for highly active relapsing MS associated with rapidly evolving disability by the EMA. It is recommended for SPMS by the guidelines of both the American Academy of Neurology (AAN) and the ECTRIMS [45,88]. Clinical studies have demonstrated that mitoxantrone reduces progression of disability and relapses in SPMS patients [90-92]. Mitoxantrone's use is limited by its associated risk of serious adverse effects (AEs), including leukemia and cardiotoxicity [93-95]. The AAN guidelines recommend that mitoxantrone only be prescribed in cases where the potential therapeutic benefits greatly outweigh the risks [45].

In some studies, interferons $(\beta-1 \mathrm{a}, \beta-1 \mathrm{~b})$ have also shown reductions in the development of new lesions and relapses [96-98] and a significant short-term (3 months) delay in progression of disability in SPMS. However, these benefits were not reproduced in other studies and a Cochrane review concluded that interferons are not useful in SPMS [99-101]. A post hoc analysis was conducted by Kappos et al. [102] to explore the cause of the divergent study results between the European study (EU-SPMS), which demonstrated significant slowing of disease progression with IFN- $\beta-1 \mathrm{~b}$ [88], and the North American study (NA-SPMS), which found no such benefit [99]. The authors identified significant differences in the patient characteristics: the patient cohort in EU-SPMS had earlier and more active disease than the NA-SPMS population. Furthermore, the rate of progression (46\%) and annual relapse rate $(0.63 /$ year) were significantly higher in EU-SPMS than in NA-SPMS ( $34 \%$ and $0.28 /$ year, respectively). The FDA approved IFN- $\beta-1 \mathrm{a}$ and $\beta-1 \mathrm{~b}$ for relapsing forms of MS [103-106]. The EMA approved IFN- $\beta-1 \mathrm{~b}$ for the management of SPMS patients with active disease, evidenced by relapses $[107,108]$. In Canada, IFN- $\beta-1 \mathrm{~b}$ is approved for the slowing of progression in disability and the reduction of the frequency of clinical exacerbations in SPMS patients $[109,110]$, and IFN- $\beta-1 \mathrm{a}\left(\operatorname{Rebif}^{\circledR}\right)$ is approved for relapsing forms of MS [111]. According to the AAN guidelines, IFN- $\beta-1 \mathrm{a}$ and $\beta-1 \mathrm{~b}$ regimens are useful for the reduction of the risk of relapse but do not delay progression [45]. The ECTRIMS guidelines support consideration of IFN- $\beta-1 \mathrm{a}$ (subcutaneous [sc]) or $\beta-1 \mathrm{~b}$ for patients with active SPMS after taking into account the 'dubious efficacy' and the safety and tolerability profile [88].

In addition to the above agents, the ECTRIMS guidelines also recommend consideration of ocrelizumab in SPMS patients [88]. Ocrelizumab is approved in the USA for the treatment of patients with relapsing or primary progressive forms of MS, relapsing MS and early PPMS in Europe, and RRMS and early PPMS in Canada [112-114]. A post hoc analysis of the Phase III OPERA I and II trials found that ocrelizumab significantly reduced disability accumulation and progression relative to IFN- $\beta-1 \mathrm{a}$ in a subgroup of patients at higher risk of SPMS (baseline EDSS $\geq 4.0$ and pyramidal Kurtzke Functional Systems Score $\geq 2$ ) [115]. When considering the use of ocrelizumab for SPMS, a careful evaluation of the patient populations in the OPERA and ORATORIO trials relative to other agents approved for relapsing MS and SPMS should be taken into account (Table 2) [84,89,90,96,99,102,116-118]. The mean time since symptom onset was much shorter (6.7 years) in ORATORIO and OPERA, and patients had markedly more $\mathrm{T}_{1}$-weighted lesions in ORATORIO. Patients were also excluded from ORATORIO if they had previously been treated with therapies for RRMS. Additionally, by nature of PPMS, a baseline history of relapses was rare in the ORATORIO cohort. In OPERA, mean EDSS ranged from 2.75 to 2.86 across treatment groups, and was 4.7 in ORATORIO.

The AAN guidelines cite insufficient evidence to make specific recommendations regarding the ability of some other treatment options (azathioprine, corticosteroids, cyclophosphamide, immunoglobulins, methotrexate) to reduce progression of disability, and deemed others (subcutaneous cladribine, glatiramer acetate) possibly no more effective than placebo to lower the risk of disability progression in SPMS [45]. These indefinite conclusions reflect problems that exist with SPMS trial methodology, particularly with respect to heterogeneity of patient populations, including characteristics such as presence/absence of inflammation-associated relapses, age and disease duration $[25,119,120]$. Furthermore, SPMS trial design also suffers from an absence of clear outcome measures 
Table 2. Baseline characteristics of patients in secondary-progressive multiple sclerosis and relapsing multiple sclerosis

clinical trials of therapies with current regulatory approval for secondary-progressive multiple sclerosis.

\begin{tabular}{|c|c|c|c|c|c|}
\hline Characteristic & Siponimod [84] & Cladribine $^{\dagger}[89]$ & Mitoxantrone ${ }^{\ddagger}, \S[90]$ & $\begin{array}{l}\text { IFN- } \beta-1 b \text { (North } \\
\text { America) } \mathbb{I}[99,102]\end{array}$ & $\begin{array}{l}\text { IFN- } \beta-1 b \\
\text { (Europe) })^{\#}[96,102,116]\end{array}$ \\
\hline Number of patients; $n$ & 1105 & 433 & 60 & 317 & 360 \\
\hline Mean age; years (SD) & $48.0(7.8)$ & $37.9(10.3)$ & $39.9(6.8)$ & $46.1(0.45)^{\dagger \dagger}$ & $41.1(7.2)$ \\
\hline Previous DMT use; \% & 77.8 & 26.1 & NR & NR & NR \\
\hline $\begin{array}{l}\text { Mean disease duration } \\
\text { from first onset; years } \\
\text { (SD) }\end{array}$ & $17.1(8.4)$ & $7.9(7.2)$ & $9.6(6.9)^{\ddagger \ddagger}$ & $14.6(0.44)^{\dagger \dagger}$ & $12.8(6.6)$ \\
\hline $\begin{array}{l}\text { EDSS score: } \\
\text { - Mean (SD) } \\
\text { - Median (range) }\end{array}$ & $\begin{array}{l}\text { NR } \\
6.0(2.0-7.0)\end{array}$ & $\begin{array}{l}2.8(1.2) \\
N R\end{array}$ & $\begin{array}{l}4.4(1.0) \\
\text { NR }\end{array}$ & $\begin{array}{l}5.2(0.06)^{\dagger \dagger} \\
\text { NR }\end{array}$ & $\begin{array}{l}5.1(1.1) \\
\text { NR }\end{array}$ \\
\hline $\begin{array}{l}\text { Gd-enhancing } \\
\mathrm{T}_{1} \text {-weighted lesions: } \\
\text { - Patients with lesions (\%) } \\
\text { - Mean number of lesions } \\
\text { (SD) }\end{array}$ & $\begin{array}{l}21.4 \\
N R\end{array}$ & $\begin{array}{l}31.9 \\
1.0(2.7)\end{array}$ & $\begin{array}{l}N R \\
N R\end{array}$ & $\begin{array}{l}\text { NR } \\
1.5(N R)\end{array}$ & $\begin{array}{l}\text { NR } \\
2.6(N R)\end{array}$ \\
\hline $\begin{array}{l}\text { Relapses in year before } \\
\text { screening }\end{array}$ & $20.5 \%$ & $100 \% \S \S$ & $1.3 \mathbb{\Psi}$ & $0.8 \mathbb{I}(0.06)^{\dagger \dagger}$ & $68.1 \% \# \#$ \\
\hline
\end{tabular}

†Data for the cladribine $3.5 \mathrm{mg} / \mathrm{kg}$ arm.

‡Data for the mitoxantrone $12 \mathrm{mg} / \mathrm{m}^{2}$ arm

$\S$ Patient population was mixed between worsening relapsing-remitting (47\%) and secondary-progressive multiple sclerosis (53\%).

IData for the IFN- $\beta-1 \mathrm{~b} 250 \mu \mathrm{g}$ arm.

\#Data for the the IFN- $\beta-1 \mathrm{~b}$ arm.

$\dagger$ †tandard error of the mean.

¥Duration of multiple sclerosis.

$\S \S$ Inclusion criterion.

IIMean number.

\#\#Relapses in 2 years before study.

DMT: Disease-modifying treatment; EDSS: Expanded Disability Status Scale; Gd: Gadolinium; NR: Not reported; SD: Standard deviation.

that reflect disability progression. This is likely related to an incomplete understanding of the mechanisms of progression [25,119-122], in addition to other factors. Finally, accumulating evidence suggests that trial durations for progressive MS trials should extend beyond the requisite 2 years to adequately evaluate for a treatment response [123]. Overcoming these complex issues will require concerted efforts from clinical and scientific communities [124].

\section{Nonpharmacological}

Holistic care is essential for a complex disorder like MS, and involves allied healthcare personnel such as physiotherapists, occupational therapists, speech/language pathologists, neuropsychologists, psychiatrists, social workers and others to address the individual patient's specific constellation of symptoms and complex psychosocial needs [125,126]. A balance must be achieved between the patient's objective of preserving health-related QoL (HRQoL) and a 'normal' life with the decreasing physical and cognitive capability that is inherent with progressive disease [72]. Lifestyle modifications as a means to minimize the impact of disease progression have been shown to be beneficial for both patients and caregivers [127]. Self-management programs should reflect the individual patient's circumstances, goals and concerns [128]. Access to patient services may be restricted, however, by regional availability, financial coverage, environmental barriers (e.g., transportation for wheelchair-dependent patients) and lack of time [129-131].

Mobility is an integral factor of both physical and emotional well-being for people living with MS. Balance/gait difficulty was the most commonly identified symptom (88.6\%) among SPMS patients and the second most common symptom (69.9\%) behind fatigue in RRMS patients [132]. When MS patients were asked to prioritize 13 bodily functions, lower limb function was rated as the highest priority by both those with early disease ( $<5$ years) and those with longer disease durations ( $>15$ years) [133]. To most patients, loss of mobility is equivalent to loss of independence [133-135]. Thus, physical therapy is an essential component of ongoing care at all stages of MS.

Progressive MS patients derived benefit from various methods of physiotherapy, including exercise therapy, functional electrical stimulation, inspiratory muscle training, therapeutic standing and body weight-supported treadmill training. According to a recent meta-analysis, patients following these regimens experienced improvements in functional independence, mobility, depression, social experience, cognitive function, HRQoL and fatigue [136. Specifically, a 6-week multidisciplinary rehabilitation program was associated with improvements in 
disability as measured by the functional independence measure, as well as in depression, social experience, QoL and fatigue [137,138]. Functional electrical stimulation was useful for gait quality, walking speed and endurance [136]. Exercise has been shown to positively affect many MS symptoms, including moderate improvements in fatigue and cardiorespiratory fitness [139-141], small but consistent benefits in balance and depressive symptoms [142-144], and can even ameliorate cognitive deficits $[145,146]$. In progressive MS patients, aerobic training was associated with improvements in walking ability, decreases in depressive symptom and fatigue, and improvements in several domains of cognitive function [147]. Exercise can even be beneficial in patients with progressive MS and in those with severe mobility impairment. In a recent study, patients who were randomized to 3 weekly 30 -min sessions of either total-body recumbent stepper training or to body weight-supported treadmill testing over 12 weeks experienced improved HRQoL and reduced fatigue [148].

Ongoing clinical trials, including a multicenter study supported by the International Progressive MS Alliance (www.progressivemsalliance.org) evaluating the benefits of exercise and cognitive-behavioral therapy in progressive MS, will provide more robust evidence regarding the benefits of these therapies.

\section{Complementary \& alternative therapies}

Complementary and alternative therapies encompass a wide array of interventions, including dietary supplements and biological products, mind-body medicine (e.g., hypnosis, biofeedback, mindfulness), and manipulative and body-based practices [149]. In the American Academy of Neurology's 2014 guidelines on complementary and alternative medicine in MS: there was insufficient evidence from unbiased, well-designed studies to evaluate many complementary and alternative products and practices associated with claims of efficacy in patients with MS [149]. Other products were determined to have a degree of effectiveness in the management of MS-related symptoms, such as cannabinoids for spasticity and pain (level A evidence), magnetic therapy (level B) and ginkgo biloba (level C) for fatigue, and reflexology (level C) for paresthesias. Given the scarcity of patient-directed materials on SPMS, many patients and/or caregivers seek information online from sources that may not accurately report the value or efficacy of complementary or alternative therapies. Some patients may request or seek out unproven, invasive and potentially dangerous therapies in an attempt to delay or stop progression $[37,150]$. Individual responses to over-the-counter products from pharmacies or health food stores may vary significantly in terms of AEs or negative interactions with prescription medication [151]. Informed guidance by physicians and allied health professionals involved in a specific patient's care is important to distinguish evidence-based therapies from ineffective alternative treatments.

\section{Patients \& caregivers}

Patients and caregivers must be active contributors in the management strategy for their SPMS, and should be encouraged to share their treatment priorities and expectations. Alterations to the existing treatment strategy particularly discontinuation of DMTs - may be difficult for the patient due to a sense of abandonment and possible loss of hope in the 'curative' potential of their therapy [49,152]. The need for education about their transition and changes to their therapeutic strategy was considered as 'critical' for patients and caregivers in one study [39]. Nonpharmacological treatment strategies are fundamental to enhance self-management, and can empower patients with SPMS and caregivers who frequently feel overwhelmed.

\section{Neurologists}

The transition to SPMS generally prompts a change in treatment strategy from relapse-reducing DMTs and options that modify the disease course during RRMS to other therapies that may delay progression of disability in progressive forms of MS [39,153]. The recent emergence of DMTs that may be beneficial in SPMS provides new therapeutic options to discuss with patients (Figure 1).

DMT continuation or escalation to a second-line agent may be beneficial in 'active' SPMS patients with relapses or MRI-detected new/enlarging lesion formation; however, there is little clinical evidence to support general DMT use in SPMS patients without evidence of clinical or MRI disease activity [45,154]. The Multiple Sclerosis Coalition Patient Survey found that $37 \%$ of patients with diagnosed or suspected SPMS were not taking any DMTs, $21 \%$ were taking ocrelizumab and $75 \%$ were taking symptom-directed therapies [74]. Physicians report that they exercise caution in escalating DMTs in SPMS patients due to concern over serious AEs and the balance of treatment benefit and risk, particularly in older patients [129]. 
1. Start or dose adjust one medication at a time

2. Target more than one symptom whenever possible

3. Start at low doses, and titrate dose up slowly when there is evidence of a response

4. Have a clear follow-up plan in place to regularly assess for medication efficacy

Reprinted with permission from [155] (c) Elsevier (2018).

After patients transition to SPMS, the focus of management should be on reducing factors that increase the risk of disability, symptom management, rehabilitation and treatment of co-morbidities. Recommendations for the effective use of medications to manage symptoms are listed in Box 1. In this regard, involving a specialist in physical medicine and rehabilitation (i.e., a physiatrist) to assist in patient comanagement would be optimal. With expertise across various body systems (neurologic, musculoskeletal, urologic and others), and a core knowledge that includes the mechanics of gait, bracing, exercise physiology, chronic pain and wellness medicine, the role of the physiatrist is expressly to assist the patient in achieving the highest level of functional independence and QoL. Many patients highlight the importance of improved understanding of their symptoms and education regarding behavioral and/or complementary strategies [155]. Patients also commonly express a desire to address and manage the more 'hidden' symptoms (e.g., mood, cognition) [49,129]. Although a number of pharmacologic and nonpharmacologic treatment strategies exist for the symptomatic management of mood symptoms, there are limited options for the symptomatic treatment of cognition in progressive MS. There is accumulating evidence that DMTs may have a beneficial effect on cognition in SPMS: a recent subanalysis of the EXPAND study demonstrated that patients receiving siponimod experienced significant improvement in cognitive processing speed versus those on placebo [156]. Mitoxantrone was also associated with significantly superior neuropsychological outcomes versus corticosteroid therapy in SPMS patients [157]. Furthermore, in one study, IFN- $\beta$-1a resulted in a numerical but nonsignificant improvement in paced auditory serial addition test, the cognition component of the MS functional composite [158].

Education of patients and caregivers remains a key element to maximize their ability to cope [37-39]. Patients and caregivers require sufficient information on therapies to evaluate response and to identify AEs. Treatment adherence was acknowledged by patients as a significant issue, which was usually linked to the complexity of the regimen [129]. The lack of evidence-based educational materials, particularly for caregivers, was indicated as a concern by physicians [39]. The need to identify and address various self-management practices that could potentially be harmful to the patient and/or caregiver, such as incorrect patient lifting or transferring practices, was also identified by physicians.

\section{Nurses/nurse practitioners \& other allied health professionals}

Nurses/nurse practitioners play key roles in discussing treatment options with patients and caregivers to ensure that they understand possible benefits, AEs and proper administration [81,82]. Patients generally acknowledged having little knowledge about the serious AEs associated with medications [159]; thus, patient education materials about therapies were deemed to be of high importance, without causing additional anxiety. Nurses can also encourage adherence to both pharmacological and nonpharmacological treatment components, facilitate self-management practices and provide support for caregivers [49,81].

The primary objective of physiotherapy and occupational therapy in people living with MS, particularly in progressive subtypes, is to provide education regarding effective means to compensate for existing impairments and to implement modifications to behavior and environment to facilitate mobility [160]. Optimally, a physiotherapist and/or occupational therapist should be part of the patient's care team from early in the disease course. Physiotherapists contribute by assisting with educating patients and caregivers about the physical and mobility impairments associated with MS, establishing a baseline of physical abilities, and developing exercise and physical activity programs tailored to the specific patient [161]. Occupational therapists focus on functional challenges in the patient's everyday life pertaining to self-care, productivity (e.g., employment, home management, volunteer activities) and leisure [162]. In those with significant disease progression and disability accumulation, exercise is adapted to focus on seated trunk positioning and control, stretching and range of motion, and respiratory function [161]. Caregivers also require training on how to properly transfer patients from one position to another [161]. Recommendations can 
be made regarding effective use of adaptive and mobility equipment, which often necessitates educating caregivers and other family members and emphasizing that these items are tools for mobility and not obstacles [161].

Interdisciplinary strategies of management should be utilized when appropriate in all SPMS patients $[39,125,126]$. Coordination of therapy is important to efficiently maximize benefit and minimize patient and caregiver burden. Patients and caregivers noted that coordination of care was often lacking, and that they had to assume the role of the 'thread' between different healthcare providers [40]. A major issue is that not all patients have access to interdisciplinary models of care due to the limitations of local resources, travel limitations and/or cost. At several locations worldwide, coordinated care initiatives are improving the ability to provide 'one-stop' care.

\section{Monitoring \& follow-up \\ Patients \& caregivers}

For patients and their caregivers, the days, months and years after a diagnosis of SPMS typically involve significant adjustments to physical and social activities, work and other aspects of life, as well as frustration and even grief over the loss of their previous way of life [37]. Some patients are able to adapt with flexibility and resilience to respond to their new reality [37-39]. Several patients have described how they were able to cope and accept their condition, predominately through a greater focus on doing all that they were able to do while accepting new limitations $[37,38]$. Support networks are essential to assist patients and caregivers with the progression of physical and cognitive decline, combined with a frequent sense of despair and isolation [39]. Improved psychological support was noted as a specific need by patients [38].

Caregivers are generally interested in attending physician appointments to support the patient, to share information and to have questions answered by the physician; however, many have reported that they felt that their information was devalued by the physician [38]. Furthermore, few caregivers considered physicians as members of their own support network [38].

\section{Neurologists}

Ongoing monitoring to identify and evaluate disease progression, assess patient HRQoL and provide ongoing support for both patients and caregivers are essential to optimize treatment benefit. Each patient's unique SPMS course, symptom variability and the absence of established biomarkers hamper the physician's ability to precisely track clinical MS disease activity and treatment response. Several technology-based clinical tools under development may improve the ability to more accurately monitor disease in the coming years [163,164]. The current reality highlights the importance of clear, ongoing conversations with patients and the entire interdisciplinary care team when monitoring patients with SPMS. Physicians reported the challenges of communication with patients and caregivers, particularly among patients who are experiencing cognitive decline, agitation, depression or apathy [49,165]. Several physicians expressed their reliance on allied health professionals, and urged greater availability of social workers and psychological services $[49,165]$. Physicians also need to ensure that patients are following the management plan, including adherence to medications, and should regularly promote principles facilitating a healthy lifestyle and general wellness.

\section{Nurses/nurse practitioners \& other allied health professionals}

Nurses/nurse practitioners serve vital roles in the ongoing support of both patients with SPMS and caregivers, and assist with adjustment and coping with their 'changing self' [39]. This type of support is particularly important in the face of widespread perceptions among SPMS patients of abandonment by the healthcare system [81]. Nurses are able to support treatment administration, encourage adherence, monitor treatment outcomes and identify and address AEs [81]. They can also counter misconceptions of SPMS and its management [129].

\section{Conclusion}

The transition to SPMS presents a host of challenges in clinical care for patients, caregivers and physicians. As new therapeutic options become available for SPMS, it is clear that patients, caregivers and an interdisciplinary team must work together at every stage of the disease to overcome barriers in the diagnosis, treatment and monitoring of SPMS. This strategy will result in improving the HRQoL of people living with SPMS. 


\section{Future perspective}

The emergence of new disease-modifying treatments for progressive MS and the increasing emphasis of nonpharmacological strategies mark a new era in the treatment of progressive MS. Although there are a number of challenges in the clinical management of people living with progressive MS, it is evident that identification, communication, education, and interdisciplinary approaches are key to overcoming current barriers. These treatment strategies will enable the delivery of optimal care that will improve clinical outcomes and enhance the quality of life of people living with progressive MS.

Financial \& competing interests disclosure

J Oh discloses that she has received grants and personal fees from Biogen-Idec, Roche and Sanofi-Genzyme. She has also received personal fees from Novartis, EMD-Serono and Celgene outside the submitted work. T Bruno reports receiving honorarium from the MS Society of Canada, and EXCEMED as a speaker, research support grants from the Barford Foundation, and the Toronto Rehab Foundation. She has also received honorarium as an advisory board member for Novartis. $V$ Devonshire reports receiving honorarium for participating in advisory board meetings and speaking engagements for EMD Serono, Biogen, Teva Neurosciences, Novartis, Sanofi-Genzyme, Roche and Allergan. PS Giacomini reports receiving honorarium from Novartis, EMD Serono, Biogen, Sanofi Genzyme, Roche, Teva for participation in advisory boards and speaking engagements, and Actelion for participating in advisory boards outside the submitted work. F Giuliani reports grants from Biogen Canada, and personal fees from Teva Neurosciences, Merck Serono, Biogen Canada, Roche and Novartis outside this submitted work. HR Nakhaipour reports that he is a former employee of Novartis Pharmaceuticals Canada. R Schecter reports that she is an employee of Novartis Pharmaceuticals Canada. C Larochelle reports receiving research grants from EMD-Serono/Merck, as well as personal fees from Sanofi-Genzyme, Celgene, Biogen, EMD-Serono, Novartis, Roche and MedDay Pharmaceuticals SA outside this submitted work. The authors have no other relevant affiliations or financial involvement with any organization or entity with a financial interest in or financial conflict with the subject matter or materials discussed in the manuscript apart from those disclosed.

The authors thank Jeff Alexander, SNELL Medical Communication, for editorial assistance with the preparation of this paper. Editorial assistance was funded by Novartis Pharmaceuticals Canada.

\section{Open access}

This work is licensed under the Attribution-NonCommercial-NoDerivatives 4.0 Unported License. To view a copy of this license, visit http://creativecommons.org/licenses/by-nc-nd/4.0/

\section{References}

Papers of special note have been highlighted as: •• of considerable interest

1. Williams GH Jr. Multiple sclerosis - an enigma. Cleve. Clin. Q. 34(1), 1-7 (1967).

2. Wallin MT, Culpepper WJ, Campbell JD et al. The prevalence of MS in the United States: a population-based estimate using health claims data. Neurology 92(10), e1029-e1040 (2019).

3. Leray E, Moreau T, Fromont A, Edan G. Epidemiology of multiple sclerosis. Rev. Neurol. (Paris) 172(1), 3-13 (2016).

4. Multiple Sclerosis International Federation. Atlas of MS 2013: mapping multiple sclerosis around the world (2013). www.msif.org/wp-content/uploads/2014/09/Atlas-of-MS.pdf

5. Confavreux C, Vukusic S. Natural history of multiple sclerosis: a unifying concept. Brain 129(Pt 3), 606-616 (2006).

- It is one of the largest natural history studies of multiple sclerosis (MS) and revealed important insights into MS disease phenotypes, and disability progression across the spectrum of MS.

6. Popescu BF, Pirko I, Lucchinetti CF. Pathology of multiple sclerosis: where do we stand? Continuum (Minneap Minn). 19(4 Multiple Sclerosis), 901-921 (2013).

7. Kister I, Bacon TE, Chamot E et al. Natural history of multiple sclerosis symptoms. Int. J. MS. Care. 15(3), 146-156 (2013).

8. Tutuncu M, Tang J, Zeid NA et al. Onset of progressive phase is an age-dependent clinical milestone in multiple sclerosis. Mult. Scler. 19(2), 188-198 (2013).

9. Scott TF, Hackett CT, Quigley MR, Schramke CJ. Relapsing multiple sclerosis patients treated with disease modifying therapy exhibit highly variable disease progression: a predictive model. Clin. Neurol. Neurosurg. 127, 86-92 (2014).

10. Compston A, Coles A. Multiple sclerosis. Lancet 372(9648), 1502-1517 (2008).

11. Stadelmann C, Wegner C, Brück W. Inflammation, demyelination, and degeneration - recent insights from MS pathology. Biochim. Biophys. Acta 1812(2), 275-282 (2011).

12. Kutzelnigg A, Lassmann H. Pathology of multiple sclerosis and related inflammatory demyelinating diseases. Handb. Clin. Neurol. 122, 15-58 (2014). 
13. Broux B, Gowing E, Prat A. Glial regulation of the blood-brain barrier in health and disease. Semin. Immunopathol. 37(6), 577-590 (2015).

14. Lassmann H, van Horssen J, Mahad D. Progressive multiple sclerosis: pathology and pathogenesis. Nat. Rev. Neurol. 8(11), 647-656 (2012).

-. This is a comprehensive review that succinctly summarizes the existing literature on progressive MS pathology.

15. Larochelle C, Uphaus T, Prat A, Zipp F. Secondary progression in multiple sclerosis: neuronal exhaustion or distinct pathology? Trends Neurosci. 39(5), 325-339 (2016).

16. Lassmann H, Brück W, Lucchinetti C. The immunopathology of multiple sclerosis: an overview. Brain Pathol. 17(2), 210-218 (2007).

17. Lassmann H. Pathogenic mechanisms associated with different clinical courses of multiple sclerosis. Front. Immunol. 9, 3116 (2019).

18. Machado-Santos J, Saji E, Tröscher AR et al. The compartmentalized inflammatory response in the multiple sclerosis brain is composed of tissue-resident CD8 ${ }^{+}$T lymphocytes and B cells. Brain 141(7), 2066-2082 (2018).

19. Frischer JM, Weigand SD, Guo Y et al. Clinical and pathological insights into the dynamic nature of the white matter multiple sclerosis plaque. Ann. Neurol. 78(5), 710-721 (2015).

20. Bevan RJ, Evans R, Griffiths L et al. Meningeal inflammation and cortical demyelination in acute multiple sclerosis. Ann. Neurol. 84(6), 829-842 (2018).

21. Scalfari A, Romualdi C, Nicholas RS et al. The cortical damage, early relapses, and onset of the progressive phase in multiple sclerosis. Neurology 90(24), e2107-e2118 (2018).

22. Eshaghi A, Prados F, Brownlee WJ et al. MAGNIMS study group. Deep gray matter volume loss drives disability worsening in multiple sclerosis. Ann. Neurol. 83(2), 210-222 (2018).

23. Calabrese $\mathrm{M}$, Romualdi $\mathrm{C}$, Poretto $\mathrm{V}$ et al. The changing clinical course of multiple sclerosis: a matter of gray matter. Ann. Neurol. 74(1), 76-83 (2013).

24. Fisher E, Lee JC, Nakamura K, Rudick RA. Gray matter atrophy in multiple sclerosis: a longitudinal study. Ann. Neurol. 64(3), 255-265 (2008).

-. It was one of the first to demonstrate, using MRI, the importance of gray matter pathology in disability progression in MS longitudinally.

25. Fox RJ, Chataway J. Advancing trial design in progressive multiple sclerosis. Mult. Scler. 23(12), 1573-1578 (2017).

26. Weideman AM, Tapia-Maltos MA, Johnson K, Greenwood M, Bielekova B. Meta-analysis of the age-dependent efficacy of multiple sclerosis treatments. Front. Neurol. 8, 577 (2017).

27. Goldschmidt T, Antel J, Konig FB, Brück W, Kuhlmann T. Remyelination capacity of the MS brain decreases with disease chronicity. Neurology 72, 1914-1921 (2009).

28. Patrikios P, Stadelmann C, Kutzelnigg A et al. Remyelination is extensive in a subset of multiple sclerosis patients. Brain 129, 3165-3172 (2006).

29. Tomic D, Kappos L, Piani Meier D et al. Predictors of conversion to secondary progressive multiple sclerosis in patients with relapsing-remitting multiple sclerosis. Neurology 90(Suppl. 15), 2.393 (2018).

30. Koch M, Kingwell E, Rieckmann P, Tremlett H. UBC MS Clinic Neurologists. The natural history of secondary progressive multiple sclerosis. J. Neurol. Neurosurg. Psychiatry 81(9), 1039-1043 (2010).

31. Scalfari A, Neuhaus A, Daumer M, Muraro PA, Ebers GC. Onset of secondary progressive phase and long-term evolution of multiple sclerosis. J. Neurol. Neurosurg. Psychiatry 85(1), 67-75 (2014).

32. Manouchehrinia A, Zhu F, Piani-Meier D et al. Predicting risk of secondary progression in multiple sclerosis: a nomogram. Mult. Scler. 25(8), 1102-1112 (2019).

33. Paz Soldán MM, Novotna M, Abou Zeid N et al. Relapses and disability accumulation in progressive multiple sclerosis. Neurology 84(1), 81-88 (2015).

34. Feys P, Giovannoni G, Dijsselbloem N, Centonze D, Eelen P, Lykke Andersen S. The importance of a multi-disciplinary perspective and patient activation programmes in MS management. Mult. Scler. 22(Suppl. 2), 34-46 (2016).

35. Heesen C, Köpke S, Richter T, Kasper J. Shared decision making and self-management in multiple sclerosis - a consequence of evidence. J. Neurol. 254(Suppl. 2), II116-II121 (2007).

36. Morgante L, Hartley G, Lowden D, Namey M, LaRocca T, Shilling J. Decision making in multiple sclerosis: theory to practice. Int. J. MS. Care 8(4), 113-120 (2006).

37. O'Loughlin E, Hourihan S, Chataway J, Playford ED, Riazi A. The experience of transitioning from relapsing remitting to secondary progressive multiple sclerosis: views of patients and health professionals. Disabil. Rehabil. 39(18), 1821-1828 (2017).

38. Davies F, Edwards A, Brain K et al. 'You are just left to get on with it': qualitative study of patient and carer experiences of the transition to secondary progressive multiple sclerosis. BMJ Open 5(7), e007674 (2015). 
39. Deibel F, Edwards M, Edwards A. Patients', carers', and providers' experiences and requirements for support in self-management of multiple sclerosis: a qualitative study. Eur. J. Pers. Cent. Healthc. 1(2), 457-467 (2013).

40. Edmonds P, Vivat B, Burman R, Silber E, Higginson IJ. 'Fighting for everything': service experiences of people severely affected by multiple sclerosis. Mult. Scler. 13(5), 660-667 (2007).

41. Nielsen J, Saliger J, Montag C, Markett S, Nöhring C, Karbe H. Facing the unknown: fear of progression could be a relevant psychological risk factor for depressive mood states among patients with multiple sclerosis. Psychother. Psychosom. 87(3), 190-192 (2018).

42. Nazareth TA, Rava AR, Polyakov JL et al. Relapse prevalence, symptoms, and health care engagement: patient insights from the Multiple Sclerosis in America 2017 survey. Mult. Scler. Relat. Disord. 26, 219-234 (2018).

43. Lublin FD, Reingold SC, Cohen JA et al. Defining the clinical course of multiple sclerosis: the 2013 revisions. Neurology 83(3), 278-286 (2014).

-• It redefined MS subtypes to include more descriptive terms relevant to clinical care, and acknowledged the limitations of our existing classification system.

44. Inojosa H, Proschmann U, Akgün K, Ziemssen T. A focus on secondary progressive multiple sclerosis (SPMS): challenges in diagnosis and definition. J. Neurol. doi:10.1007/s00415-019-09489-5 (2019) (Epub ahead of print).

45. Rae-Grant A, Day GS, Marrie RA et al. American Academy of Neurology. Practice guideline: disease-modifying therapies for adults with multiple sclerosis. Guidelines recommendation summary. Neurology 90(17), 777-788 (2018).

46. Lorscheider J, Buzzard K, Jokubaitis V et al. MSBase Study Group. Defining secondary progressive multiple sclerosis. Brain 139(Pt 9), 2395-2405 (2016).

47. Katz Sand I, Krieger S, Farrell C, Miller AE. Diagnostic uncertainty during the transition to secondary progressive multiple sclerosis. Mult. Scler. 20(12), 1654-1657 (2014).

48. Ontaneda D, Fox RJ. Progressive multiple sclerosis. Curr. Opin. Neurol. 28(3), 237-243 (2015).

49. Davies F, Wood F, Brain KE et al. The transition to secondary progressive multiple sclerosis: an exploratory qualitative study of health professionals' experiences. Int. J. MS. Care. 18(5), 257-264 (2016).

50. Correale J, Gaitán MI, Ysrraelit MC, Fiol MP. Progressive multiple sclerosis: from pathogenic mechanisms to treatment. Brain 140(3), 527-546 (2017).

51. Kappos L, Moeri D, Radue EW et al. Predictive value of gadolinium-enhanced magnetic resonance imaging for relapse rate and changes in disability or impairment in multiple sclerosis: a meta-analysis. Lancet 353(9157), 964-969 (1999).

52. Rudick RA, Lee JC, Simon J et al. Significance of T2 lesions in multiple sclerosis: a 13-year longitudinal study. Ann. Neurol. 60(2), 236-242 (2006).

53. Fisniku LK, Brex PA, Altmann DR et al. Disability and T2 MRI lesions: a 20-year follow-up of patients with relapse onset of multiple sclerosis. Brain 131(Pt 3), 808-817 (2008).

54. Casserly C, Seyman EE, Alcaide-Leon P et al. Spinal cord atrophy in multiple sclerosis: a systematic review and meta-analysis. J. Neuroimag. 28(6), 556-586 (2018).

55. Absinta M, Sati P, Schindler M et al. Persistent 7-tesla phase rim predicts poor outcome in new multiple sclerosis patient lesions. J. Clin. Invest. 126(7), 2597-2609 (2016).

56. Christensen O, Clausen J, Fog T. Relationships between abnormal IgG index, oligoclonal bands, acute phase reactants and some clinical data in multiple sclerosis. J. Neurol. 218(4), 237-244 (1978).

57. Dobson R, Ramagopalan S, Davis A, Giovannoni G. Cerebrospinal fluid oligoclonal bands in multiple sclerosis and clinically isolated syndromes: a meta-analysis of prevalence, prognosis and effect of latitude. J. Neurol. Neurosurg. Psychiatry 84(8), 909-914 (2013).

58. Petzold A. Intrathecal oligoclonal IgG synthesis in multiple sclerosis. J. Neuroimmunol. 262(1-2), 1-10 (2013).

59. Lourenco P, Shirani A, Saeedi J, Oger J, Schreiber WE, Tremlett H. Oligoclonal bands and cerebrospinal fluid markers in multiple sclerosis: associations with disease course and progression. Mult. Scler. 19(5), 577-584 (2013).

60. Mandrioli J, Sola P, Bedin R, Gambini M, Merelli E. A multifactorial prognostic index in multiple sclerosis. Cerebrospinal fluid IgM oligoclonal bands and clinical features to predict the evolution of the disease. J. Neurol. 255(7), 1023-1031 (2008).

61. Koch M, Heersema D, Mostert J, Teelken A, De Keyser J. Cerebrospinal fluid oligoclonal bands and progression of disability in multiple sclerosis. Eur. J. Neurol. 14(7), 797-800 (2007).

62. Sellebjerg F, Royen L, Soelberg Sørensen P, Oturai AB, Jensen PEH. Prognostic value of cerebrospinal fluid neurofilament light chain and chitinase-3-like-1 in newly diagnosed patients with multiple sclerosis. Mult. Scler. 25(11), 1444-1451 (2019).

63. Bhan A, Jacobsen C, Myhr KM, Dalen I, Lode K, Farbu E. Neurofilaments and 10-year follow-up in multiple sclerosis. Mult. Scler. 24(10), 1301-1307 (2018).

64. Barro C, Benkert P, Disanto G et al. Serum neurofilament as a predictor of disease worsening and brain and spinal cord atrophy in multiple sclerosis. Brain 141(8), 2382-2391 (2018).

65. Romme Christensen J, Komori M, von Essen MR et al. CSF inflammatory biomarkers responsive to treatment in progressive multiple sclerosis capture residual inflammation associated with axonal damage. Mult. Scler. 25(7), 937-946 (2018). 
66. Zilliotto N, Marchetti G, Jakimovski D et al. CCL18 plasma levels are increased in progressive MS patients and associated with MRI outcomes of tissue injury. Neurology 90(Suppl. 15), P1.396 (2018).

67. Imrell K, Greiner E, Hillert J, Masterman T. HLA-DRB115 and cerebrospinal-fluid-specific oligoclonal immunoglobulin G bands lower age at attainment of important disease milestones in multiple sclerosis. J. Neuroimmunol. 210(1-2), 128-130 (2009).

68. Hinsinger G, Galéotti N, Nabholz N et al. Chitinase 3-like proteins as diagnostic and prognostic biomarkers of multiple sclerosis. Mult. Scler. 21(10), 1251-1261 (2015).

69. Quintana E, Coll C, Salavedra-Pont J et al. Cognitive impairment in early stages of multiple sclerosis is associated with high cerebrospinal fluid levels of chitinase 3-like 1 and neurofilament light chain. Eur. J. Neurol. 25(9), 1189-1191 (2018).

70. Håkansson I, Tisell A, Cassel P et al. Neurofilament levels, disease activity and brain volume during follow-up in multiple sclerosis. J. Neuroinflammation. 15(1), 209 (2018).

71. Harris VK, Tuddenham JF, Sadiq SA. Biomarkers of multiple sclerosis: current findings. Degener. Neurol. Neuromuscul. Dis. 7, 19-29 (2017).

72. Frost J, Grose J, Britten N. A qualitative investigation of lay perspectives of diagnosis and self-management strategies employed by people with progressive multiple sclerosis. Health (London) 21(3), 316-336 (2017).

73. Bogosian A, Morgan M, Moss-Morris R. Multiple challenges for people after transitioning to secondary progressive multiple sclerosis: a qualitative study. BMJ Open 9, e026421 (2019).

-• It comprehensively evaluated in a qualitative manner the many challenges faced by people living with secondary-progressive MS.

74. Institute for Clinical and Economic Review. Siponimod for the treatment of secondary progressive multiple sclerosis: effectiveness and value (2019). https://icer-review.org/wp-content/uploads/2018/10/ICER_MS_Revised_Scope_112918.pdf

75. Clare L, Teale JC, Toms G et al. Cognitive rehabilitation, self-management, psychotherapeutic and caregiver support interventions in progressive neurodegenerative conditions: a scoping review. NeuroRehabilitation. 43(4), 443-471 (2018).

-• It provides a comprehensive review of various interventions that can improve symptoms that are of importance to progressive MS patients, and that can provide support to caregivers, which are important unmet needs in MS clinical practice.

76. Holloway RG, Gramling R, Kelly AG. Estimating and communicating prognosis in advanced neurologic disease. Neurology 80(8), 764-772 (2013).

77. Golla H, Galushko M, Pfaff H, Voltz R. Unmet needs of severely affected multiple sclerosis patients: the health professionals' view. Palliat. Med. 26(2), 139-151 (2012).

78. Institute for Clinical and Economic Review. Disease-modifying therapies for relapsing-remitting and primary-progressive multiple sclerosis: effectiveness and value: evidence report (2017). https://icer-review.org/wp-content/uploads/2016/08/CTAF_MS_Evidence_Report_012617.pdf

79. Halper J. The evolving role of the nurse in the treatment of multiple sclerosis. J. Neurosci. Nurs. 41(4), E1-E13 (2009).

80. White B. The role of the multiple sclerosis specialist nurse in counselling patients at diagnosis. Br. J. Neurosci. Nurs. 8(4), 179-182 (2012).

81. Burke T, Dishon S, McEwan L, Smrtka J. The evolving role of the multiple sclerosis nurse: an international perspective. Int. J. MS. Care. 13(3), 105-112 (2011).

82. Sanchez MAR, Porter B. The role of the MS clinical nurse specialist in the management of disease-modifying drugs. Br. J. Neurosci. Nurs. 11(6), 273-278 (2015).

83. Novartis Inc. Mayzent ${ }^{\circledR}$ (siponimod) tablets, Prescribing Information (2019).

84. Kappos L, Bar-Or A, Cree BAC et al. Siponimod versus placebo in secondary progressive multiple sclerosis (EXPAND): a double-blind, randomised, Phase III study. Lancet 391(10127), 1263-1273 (2018).

85. EMD Serono, Inc. Mavenclad ${ }^{\circledR}$ (cladribine) tablets, Prescribing Information (2019).

86. Merck Europe BV. Mavenclad ${ }^{\circledR}$ (cladribine) tablets, Prescribing Information (2017).

87. EMD Serono, Inc. Mavenclad ${ }^{\circledR}$ (cladribine) tablets, Product Monograph (2017).

88. Montalban X, Gold R, Thompson AJ et al. ECTRIMS/EAN guideline on the pharmacological treatment of people with multiple sclerosis. Mult. Scler. 24(2), 96-120 (2018).

89. Giovannoni G, Comi G, Cook $S$ et al. A placebo-controlled trial of oral cladribine for relapsing multiple sclerosis. CLARITY Study Group. N. Engl. J. Med. 362(5), 416-426 (2010).

90. Hartung HP, Gonsette R, König N et al. Mitoxantrone in progressive multiple sclerosis: a placebo-controlled, double-blind, randomised, multicentre trial. Lancet 360(9350), 2018-2025 (2002).

91. Lasek-Bal A, Bartoszek K, Steposz A, Puz P, Bal W, Kazibutowska Z. Efficacy and safety of mitoxantrone use in primary and secondary progressive multiple sclerosis - study site experience based on the therapy of 104 patients. Int. J. Neurosci. 127(10), 859-863 (2017).

92. van de Wyngaert FA, Beguin C, D'Hooghe MB et al. A double-blind clinical trial of mitoxantrone versus methylprednisolone in relapsing, secondary progressive multiple sclerosis. Acta Neurol. Belg. 101(4), 210-216 (2001). 
93. Ellis R, Brown S, Boggild M. Therapy-related acute leukaemia with mitoxantrone: four years on, what is the risk and can it be limited? Mult. Scler. 21(5), 642-645 (2015).

94. Fleischer V, Salmen A, Kollar S et al. Cardiotoxicity of mitoxantrone treatment in a German cohort of 639 multiple sclerosis patients. J. Clin. Neurol. 10(4), 289-295 (2014).

95. Le Page E, Leray E, Edan G. Long-term safety profile of mitoxantrone in a French cohort of 802 multiple sclerosis patients: a 5-year prospective study. Mult. Scler. 17(7), 867-875 (2011).

96. Placebo-controlled multicentre randomised trial of interferon beta- $1 \mathrm{~b}$ in treatment of secondary progressive multiple sclerosis. European Study Group on interferon beta-1b in secondary progressive MS. Lancet 352(9139), 1491-1497 (1998).

97. Secondary Progressive Efficacy Clinical Trial of Recombinant Interferon-Beta-1a in MS (SPECTRIMS) Study Group. Randomized controlled trial of interferon- beta-1a in secondary progressive MS: clinical results. Neurology 56(11), 1496-1504 (2001).

98. Cohen JA, Cutter GR, Fischer JS et al. IMPACT Investigators. Benefit of interferon beta-1a on MSFC progression in secondary progressive MS. Neurology 59(5), 679-687 (2002).

99. Panitch H, Miller A, Paty D, Weinshenker B. Interferon beta-1b in secondary progressive MS: results from a 3-year controlled study. Neurology 63(10), 1788-1795 (2004).

100. Andersen O, Elovaara I, Färkkilä M et al. Multicentre, randomised, double blind, placebo controlled, Phase III study of weekly, low dose, subcutaneous interferon beta-1a in secondary progressive multiple sclerosis. J. Neurol. Neurosurg. Psychiatry 75(5), 706-710 (2004).

101. La Mantia L, Vacchi L, Di Pietrantonj C et al. Interferon beta for secondary progressive multiple sclerosis. Cochrane. Database. Syst. Rev. 1, CD005181 (2012).

102. Kappos L, Weinshenker B, Pozzilli C et al. Interferon beta-1b in secondary progressive MS: a combined analysis of the two trials. Neurology 63(10), 1779-1787 (2004).

103. Biogen. Avonex ${ }^{\circledR}$ (interferon- $\beta$-1a) intramuscular - Prescribing Information (2012).

104. EMD Serono. Rebif ${ }^{\circledR}$ (interferon- $\beta$-1a) subcutaneous - Prescribing Information (2012).

105. Berlex Laboratories. Betaseron ${ }^{\circledR}$ (interferon- $\left.\beta-1 b\right)$ - Prescribing Information (2015).

106. Novartis Pharmaceuticals. Extavia ${ }^{\circledR}$ (interferon- $\beta$-1b) subcutaneous - Prescribing Information (2018).

107. Bayer Inc. Betaferon ${ }^{\circledR}$ (interferon- $\beta$-1a): EPAR - Prescribing Information (2018).

108. Novartis Pharmaceuticals. Extavia ${ }^{\circledR}$ (interferon- $\beta-1 b$ ): EPAR - Prescribing Information (2018).

109. Bayer Inc. Betaseron ${ }^{\circledR}$ (interferon- $\beta-1 b$ ) subcutaneous - Product Monograph (2016).

110. Novartis Pharmaceuticals Canada. Extavia ${ }^{\circledR}$ (interferon- $\left.\beta-1 b\right)$ subcutaneous - Product Monograph (2016).

111. EMD Serono. Rebif ${ }^{\circledR}$ (interferon- $\beta$-1a) - Product Monograph (2016).

112. Genentech Inc. Ocrevus (ocrelizumab) - Patient Information (2017).

113. Roche Pharma AG. Ocrevus (ocrelizumab): EPAR - Prescribing Information (2019).

114. Hoffmann-La Roche Ltd. Ocrevus (ocrelizumab) - Product Monograph (2019).

115. Kappos L, Wolinsky JS, Giovannoni G et al. Ocrelizumab reduces disability progression independent of relapse activity in patients with relapsing multiple sclerosis (RMS) (abstract). J. Neurol. Neurosurg. Psychiatry 89(6), e061 (2018).

116. Kappos L, Polman C, Pozzilli C et al. Final analysis of the European multicenter trial on IFNbeta-1b in secondary-progressive MS. Neurology 57(11), 1969-1975 (2001).

117. Montalban X, Hauser SL, Kappos L et al. Ocrelizumab versus placebo in primary progressive multiple sclerosis. N. Engl. J. Med. 376(3), 209-220 (2017).

118. Hauser SL, Bar-Or A, Comi G et al. Ocrelizumab versus interferon beta-1a in relapsing multiple sclerosis. N. Engl. J. Med. 376(3), 221-234 (2017).

119. Mills EA, Begay JA, Fisher C, Mao-Draayer Y. Impact of trial design and patient heterogeneity on the identification of clinically effective therapies for progressive MS. Mult. Scler. doi:10.1177/1352458518800800 (2018) (Epub ahead of print).

120. Tur C, Montalban X. Progressive MS trials: lessons learned. Mult. Scler. 23(12), 1583-1592 (2017).

121. Ontaneda D, Cohen JA, Amato MP. Clinical outcome measures for progressive MS trials. Mult. Scler. 23(12), 1627-1635 (2017).

122. Plantone D, De Angelis F, Doshi A, Chataway J. Secondary progressive multiple sclerosis: definition and measurement. CNS. Drugs 30 , 517-526 (2016).

123. Giovannoni G, Cutter G, Sormani MP et al. Is multiple sclerosis a length-dependent central axonopathy? The case for therapeutic lag and the asynchronous progressive MS hypotheses. Mult. Scler. Relat. Disord. 12, $70-78$ (2017).

124. Salvetti M, Landsman D, Schwarz-Lam P, Comi G, Thompson AJ, Fox RJ. Progressive MS: from pathophysiology to drug discovery. Mult. Scler. 21(11), 1376-1384 (2015).

125. Gallien P, Gich J, Sánchez-Dalmau BF, Feneberg W. Multidisciplinary management of multiple sclerosis symptoms. Eur. Neurol. 72(Suppl. 1), 20-25 (2014). 
126. Ross AP. Management of multiple sclerosis. Am. J. Manag. Care. 19(Suppl. 16), S301-S306 (2013).

127. Neate SL, Taylor KL, Jelinek GA, De Livera AM, Brown CR, Weiland TJ. Psychological shift in partners of people with multiple sclerosis who undertake lifestyle modification: an interpretive phenomenological study. Front. Psychol. 9, 15 (2018).

128. Yoward S, Stannage E, Whiffin L, Dawson P. The self-management needs of those who have primary or secondary progressive multiple sclerosis. Physiotherapy. 103(Suppl. 1), e90 (2017).

129. Members of the MS in the 21st Century Steering Group; Rieckmann P, Centonze D et al. Unmet needs, burden of treatment, and patient engagement in multiple sclerosis: a combined perspective from the MS in the 21 st Century Steering Group. Mult. Scler. Relat. Disord. 19, 153-160 (2018).

-. This statement provides a general overview of evolving MS clinical care, and summarizes many important issues in clinical practice that are often overlooked.

130. Lonergan R, Kinsella K, Fitzpatrick P et al. Unmet needs of multiple sclerosis patients in the community. Mult. Scler. Relat. Disord. 4(2), 144-150 (2015).

131. Golla H, Galushko M, Pfaff H, Voltz R. Unmet needs of severely affected multiple sclerosis patients: the health professionals' view. Palliat. Med. 26(2), 139-151 (2012).

132. Gross HJ, Watson C. Characteristics, burden of illness, and physical functioning of patients with relapsing-remitting and secondary progressive multiple sclerosis: a cross-sectional US survey. Neuropsychiatr. Dis. Treat. 13, 1349-1357 (2017).

133. Heesen C, Böhm J, Reich C, Kasper J, Goebel M, Gold SM. Patient perception of bodily functions in multiple sclerosis: gait and visual function are the most valuable. Mult. Scler. 14, 988-991 (2008).

134. Finlayson M. Concerns about the future among older adults with multiple sclerosis. Am. J. Occup. Ther. 58, 54-63 (2004).

135. Vazirinejad R, Lilley JM, Ward CD. The 'Impact on Participation and Autonomy': acceptability of the English version in a multiple sclerosis outpatient setting. Mult. Scler. 9(6), 612-615 (2003).

136. Campbell E, Coulter EH, Mattison PG, Miller L, McFadyen A, Paul L. Physiotherapy rehabilitation for people with progressive multiple sclerosis: a systematic review. Arch. Phys. Med. Rehabil. 97(1), 141-151 (2016).

137. Patti F, Ciancio MR, Cacopardo M et al. Effects of a short outpatient rehabilitation treatment on disability of multiple sclerosis patients - a randomised controlled trial. J. Neurol. 250(7), 861-866 (2003).

138. Patti F, Ciancio MR, Reggio E et al. The impact of outpatient rehabilitation on quality of life in multiple sclerosis. J. Neurol. 249(8), 1027-1033 (2002).

139. Asano M, Berg E, Johnson K, Turpin M, Finlayson ML. A scoping review of rehabilitation interventions that reduce fatigue among adults with multiple sclerosis. Disabil. Rehabil. 37(9), 729-738 (2015).

140. Heine M, van de Port I, Rietberg MB, van Wegen EE, Kwakkel G. Exercise therapy for fatigue in multiple sclerosis. Cochrane. Database. Syst. Rev.(9), CD009956 (2015).

141. Platta ME, Ensari I, Motl RW, Pilutti LA. Effect of exercise training on fitness in multiple sclerosis: a meta-analysis. Arch. Phys. Med. Rehabil. 97(9), 1564-1572 (2016).

142. Paltamaa J, Sjögren T, Peurala SH, Heinonen A. Effects of physiotherapy interventions on balance in multiple sclerosis: a systematic review and meta-analysis of randomized controlled trials. J. Rehabil. Med. 44(10), 811-823 (2012).

143. Ensari I, Motl RW, Pilutti LA. Exercise training improves depressive symptoms in people with multiple sclerosis: results of a meta-analysis. J. Psychosom. Res. 76(6), 465-471 (2014).

144. Adamson BC, Ensari I, Motl RW. Effect of exercise on depressive symptoms in adults with neurologic disorders: a systematic review and meta-analysis. Arch. Phys. Med. Rehabil. 96(7), 1329-1338 (2015).

145. Sandroff BM, Pilutti LA, Benedict RH, Motl RW. Association between physical fitness and cognitive function in multiple sclerosis: does disability status matter? Neurorehabil. Neural. Repair. 29(3), 214-223 (2015).

146. Sandroff BM, Motl RW, Scudder MR, DeLuca J. Systematic, evidence-based review of exercise, physical activity, and physical fitness effects on cognition in persons with multiple sclerosis. Neuropsychol. Rev. 26(3), 271-294 (2016).

147. Briken S, Gold SM, Patra S et al. Effects of exercise on fitness and cognition in progressive MS: a randomized, controlled pilot trial. Mult. Scler. 20(3), 382-390 (2014).

148. Pilutti LA, Paulseth JE, Dove C, Jiang S, Rathbone MP, Hicks AL. Exercise training in progressive multiple sclerosis: a comparison of recumbent stepping and body weight-supported treadmill training. Int. J. MS. Care. 18(5), 221-229 (2016).

149. Yadav V, Bever C Jr, Bowen J et al. Summary of evidence-based guideline: complementary and alternative medicine in multiple sclerosis: report of the Guideline Development Subcommittee of the American Academy of Neurology. Neurology 82, 1083-1092 (2014).

-. This is an excellent evidence-based summary of various complementary and alternative therapies in MS, which commonly come up in clinical practice.

150. National Multiple Sclerosis Society. Clear thinking about alternative therapies: staying well (2011). www.nationalmssociety.org/National MSSociety/media/MSNationalFiles/Brochures/Brochure-Clear-Thinking-About-Alternative-Therapies.pdf 
151. National Multiple Sclerosis Society. Complementary \& alternative medicines. www.nationalmssociety.org/Treating-MS/Complementary-Alternative-Medicines

152. Miller AE. Switching or discontinuing disease-modifying therapies for multiple sclerosis. Continuum. (Minneap. Minn.) 22(3), 851-863 (2016).

153. Thompson AJ. Challenge of progressive multiple sclerosis therapy. Curr. Opin. Neurol. 30(3), 237-240 (2017).

154. Freedman MS, Selchen D, Prat A, Giacomini PS. Managing multiple sclerosis: treatment initiation, modification, and sequencing. Can. J. Neurol. Sci. 45(5), 489-503 (2018).

155. Crabtree-Hartman E. Advanced symptom management in multiple sclerosis. Neurol. Clin. 36(1), 197-218 (2018).

156. Benedict RHB, Cree B, Tomic D et al. Impact of siponimod on cognition in patients with secondary progressive multiple sclerosis: results from Phase 3 EXPAND study (S44.004). Presented at: 70th Annual Meeting of the American Academy of Neurology, Los Angeles, CA, USA, 21-27 April 2018.

157. Kinner M, Hoepner R, Klotz P et al. Immunotherapy improves cognitive function in secondary progressive multiple sclerosis [letter]. CNS. Neurosci. Ther. 22(12), 1019-1022 (2016).

158. Cohen JA, Cutter GR, Fischer JS et al. IMPACT Investigators. Benefit of interferon beta-1a on MSFC progression in secondary progressive MS. Neurology 59(5), 679-687 (2002).

159. Hofmann A, Stellmann JP, Kasper J et al. MS Network Hamburg. Long-term treatment risks in multiple sclerosis: risk knowledge and risk perception in a large cohort of mitoxantrone-treated patients. Mult. Scler. 19(7), 920-925 (2013).

160. National Multiple Sclerosis Society. Rehabilitation paradigm. www.nationalmssociety.org/For-Professionals/Clinical-Care/Managing-MS/Rehabilitation/Rehabilitation-Paradigm

161. Rohring M. Physical Therapy in Multiple Sclerosis: A Resource for Healthcare Professionals. National Multiple Sclerosis Society (2018). www.nationalmssociety.org/For-Professionals/Clinical-Care/Managing-MS/Rehabilitation/Rehabilitation-Paradigm

162. Ghahari S, Finlayson M. Occupational Therapy in Multiple Sclerosis Rehabilitation: A Resource for Healthcare Professionals. National Multiple Sclerosis Society (2018). www.nationalmssociety.org/For-Professionals/Clinical-Care/Managing-MS/Rehabilitation/Rehabilitation-Paradigm

163. Rudick RA, Miller D, Bethoux F et al. The Multiple Sclerosis Performance Test (MSPT): an iPad-based disability assessment tool. J. Vis. Exp. 88, e51318 (2014).

164. Montalban X, Mulero P, Midaglia L et al. FLOODLIGHT remote self-monitoring is accepted by patients and provides meaningful, continuous sensor-based outcomes consistent with and augmenting conventional in-clinic measures. Presented at:The 70th American Academy of Neurology (AAN) Annual Meeting, Los Angeles, CA, USA. 21-27 April 2018 (Poster 382).

165. Borreani C, Bianchi E, Pietrolongo E et al. PeNSAMIproject. Unmet needs of people with severe multiple sclerosis and their carers: qualitative findings for a home-based intervention. PLoS ONE 9(10), e109679 (2014). 
